\title{
Produção de materiais de orientação para compras em formato delivery na região de Picos (Piauí) durante a pandemia de COVID-19
}

\section{Production of guidance materials for purchases in delivery format in the region of Picos (Piauí, Brazil) during the COVID-19 pandemic}

\author{
Heleonardo Dandas de Melo' iD \\ Maria Eduarda Mauriz \\ Rodrigues" (iD \\ Wilton do Amaral Alves"II (iD \\ Rubens de Carvalho Almondes'
}

Shara Lylian de Castro Lopes' iD

Vicente Medeiros Carvalho'

Rui Marques Carvalho'

David Ariel Sousa Torres

Araújolv iD

\section{RESUMO}

Introdução: A rápida disseminação da COVID-19 tem solicitado a propositura de ações igualmente ágeis no sentido de contenção do contágio da doença, ao mesmo passo o comércio é pressionado a buscar novas estratégias de vendas para reduzir os impactos econômicos. Essas ações devem observar sobretudo evidências científicas a fim de zelar pela saúde da população. Objetivo: Expor o processo de formulação de protocolos escritos e encartes gráficos educativos, no sentido de diminuir a transmissão viral do SARSCoV-2 por meio de compras na modalidade delivery. Método: Trata-se de um trabalho descritivo das etapas de elaboração de uma tecnologia de intervenção para a cidade de Picos (Piauí) durante a pandemia de COVID-19, a partir da coleta de informações em bases científicas e disponibilizadas por instituições renomadas. Resultados: Obteve-se protocolos adequados às peculiaridades de cada cliente e comerciante. 0 resultado final, em formato de folhetos ilustrados, recebeu selo de aprovação da Fundação Oswaldo Cruz, na sua ação complementar à campanha "Se Liga no Corona". Conclusões: Os protocolos se apresentam como uma possibilidade de promoção da conscientização em relação às práticas de compras delivery, sendo necessário nos próximos estudos avaliar a aplicabilidade dos folhetos, acompanhar sua eficácia e possíveis necessidades de reformulação.

PALAVRAS-CHAVE: Protocolos Informativos; Entregas Delivery; COVID-19; Conscientização
1 Instituto Federal de Educação Ciência e Tecnologia do Piauí (IFPI), Picos, PI, Brasil

" Universidade Federal do Delta do Parnaíba (UFDPar), Parnaíba, PI, Brasil

III Universidade Federal de Campina Grande (UFCG), Campina Grande, PB, Brasil

Iv Instituto Educacional Raimundo de Sá Filho, Picos, PI, Brasil

\section{* E-mail: heledoc@ifpi.edu.br}

\begin{abstract}
Introduction: The rapid spread of COVID-19 has prompted the proposition of likewise agile actions in order to contain the contagion of the disease, while the trade is under pressure to seek new sales strategies to reduce economic impacts. These actions must mainly observe scientific evidence in order to ensure the health of the population. Objective: To expose the process of formulating written protocols and educational graphic inserts, in order to reduce the viral transmission of SARS-CoV-2 through purchases in the delivery mode. Method: This is a descriptive work of the stages of development of an intervention technology for the city of Picos (Piauí, Brazil) during the COVID-19 pandemic, based on the collection of information on scientific bases made available by renowned institutions. Results: Flexible protocols were obtained to the peculiarities of each customer and trader. The final result, in the form of illustrated leaflets, received a seal of approval by Oswaldo Cruz Foudation, in its complementary action to the "Se Liga no Corona" campaign. Conclusions: It is concluded that the protocols are presented as a possibility of promoting awareness in relation to the delivery shopping practices, resting necessary for the next studies to evaluate the applicability of the brochures, and to monitor their effectiveness and possible reformulation needs.
\end{abstract}

KEYWORDS: Information Protocols; Deliveries Delivery; COVID-19; Awareness 


\section{INTRODUÇÃO}

O vírus nomeado SARS-CoV-2, responsável pela COVID-19, impôs ao Brasil o desafio de saúde pública do século atual, situação enfrentada mundialmente, já que a doença configurou um cenário de pandemia. A rapidez de propagação do vírus impossibilita que o conhecimento científico, forte aliado na busca por uma saída ao problema, seja suficiente para conter os impactos em números de contaminados e mortos, bem como impedir os seus diversos efeitos econômicos, sociais e psicológicos negativos.

Tal obstáculo se evidencia pela ausência de uma vacina ou tratamento efetivo (ainda que várias vacinas já estejam sendo desenvolvidas e testadas em vários países) ${ }^{1}$, limitando os planos de contingência à expansão da rede hospitalar, identificação dos casos, prevenção e interrupção ou diminuição da cadeia de transmissão. Diante disso, a Organização Mundial da Saúde (OMS) tem preconizado medidas higiênicas e de distanciamento social como as mais eficientes no combate à pandemia até o momento ${ }^{2}$. Essas medidas devem ser pautadas sobretudo pela educação e pela conscientização da população e orientadas por bases científicas.

Diante do exposto, no sentido de colaborar com medidas que tenham o potencial de reduzir a velocidade de contaminação por SARS-CoV-2, o grupo de pesquisa Base Observacional Interdisciplinar Laboratorial para Extensão, Pesquisa e Sociologia (BOILES), vinculado ao Instituto Federal de Educação Ciência e Tecnologia do Piauí (IFPI), realizou a produção de protocolos escritos e encartes gráficos educativos para circulação na comunidade picoense (da região de Picos, cidade localizada no Centro-Sul do Piauí). 0 objetivo principal deste trabalho foi expor a criação dos referidos protocolos que objetivaram sobretudo diminuir a possibilidade de transmissão viral durante o procedimento de compras na modalidade delivery.

Salienta-se que, desde o início das medidas de isolamento no combate à pandemia, um dos impactos na estrutura econômica foi o modo de operação dos mais variados empreendimentos, principalmente os pequenos negócios. O Serviço Brasileiro de Apoio às Micro e Pequenas Empresas (Sebrae) estima que 5,3 milhões de pequenos empreendimentos comerciais, até o início de abril, efetivaram mudanças bruscas em seu funcionamento. Desse total, $41,9 \%$ se refere a mudanças que incluem a implementação de medidas envolvendo compras, vendas e entregas online ${ }^{3}$.

Esse projeto de produção de protocolos e folhetos se direciona no sentido de centralizar esforços em torno dessa modalidade de compras, que concatena alternativas para redução de impactos na economia, medidas de controle e, ao mesmo tempo, redução na possibilidade de contágio.

\section{MÉTODO}

A estruturação dos protocolos de delivery foi pensada a partir de três cenários-base, a saber: 1) pagamento com cartão de crédito/débito, 2) pagamento com dinheiro e 3) pagamento por transferência bancária. A perspectiva era que o cliente não precisasse sair de casa para efetuar compras, diminuindo, dessa forma, a possibilidade de seu contágio direto ou indireto.

Para o embasamento das informações, verificamos estudos referentes a vetores de contaminação da COVID-19 e publicações em sites oficiais que traziam recomendações especializadas de higienização pessoal, de produtos e de embalagens. Estes estudos orientaram os passos lógicos dos protocolos construídos, bem como a utilização dos materiais e de equipamentos de proteção para sua aplicação, com base no seguinte tripé: higienização, uso de máscara e manutenção de distância entre as pessoas envolvidas.

Acerca do uso de máscara durante a aplicação dos protocolos, recomendação notória e amplamente divulgada, seguimos as orientações da $\mathrm{OMS}^{4}$, a partir de trabalhos que versam sobre os efeitos de sua limitação para a contaminação $0^{5}$. Além desses trabalhos, consideramos indicações de estudos que apontam elevada carga viral na garganta de infectados e demonstrações de que o risco de contágio pode acontecer durante ou mesmo antes do início dos sintomas, aumentando, portanto, a possibilidade de contaminação por pré-sintomáticos ${ }^{6}$.

Esse dado direcionou para a necessidade de ajustes em medidas de controles e prevenção quando do contato entre indivíduos, mesmo que estes não apresentem sintomas, sendo o uso de máscaras uma das medidas de precaução possível de ser tomada. Salienta-se também a possibilidade de proteção proporcionada pela máscara no contato com indivíduos assintomáticos, enquanto a importância do nível de vetores de contaminação dos indivíduos que não apresentam sintomas não é totalmente esclarecida ${ }^{7}$.

Recorremos também a estudos indicativos de que o contato próximo ou a transmissão de curto alcance por gotículas de salivas contaminadas seriam a principal forma de propagação da COVID-19, bem como a transmissão através dos aerossóis produzidos pela respiração, tosse e espirro ${ }^{8,9}$. Desse modo, o uso de máscaras, a fim de bloquear ou diminuir a propagação de gotículas contaminadas e seu contato com pessoas saudáveis, é apontado como estratégia para desacelerar a propagação da doença.

As indicações para os procedimentos de higienização das embalagens dos produtos, das caixas de papelão ou plástico utilizadas e de todas as superfícies usadas ou acessadas durante o recebimento das mercadorias estão norteadas por estudos que sugerem elevada variação da viabilidade infeciosa do SARS-CoV-2 conforme temperatura, superfície e tempo de exposição9,10. A apresentação do SARS-CoV-2 como mais instável em plástico e aço inoxidável do que em papelão, porém encontrado viável até $72 \mathrm{~h}$ nessas áreas ${ }^{9}$, foi preponderante para a indicação nos protocolos da higienização total de todas as superfícies e materiais envolvidos durante o processo de entrega e recebimento dos produtos adquiridos pela modalidade delivery. 
A forma de higienização exposta nos protocolos segue as orientações da OMS repercutidas por órgãos oficiais nacionais, indicando a higiene pessoal com o uso de água e sabão ${ }^{11}$. Além disso, foram consultados outros estudos que indicam os efeitos de inviabilização do vírus por meio do hipoclorito de sódio e etanol ${ }^{12,13}$. Consideramos, ainda, as orientações do Ministério da Saúde a respeito da distância que deve ser mantida entre as pessoas para diminuir a possibilidade de contágio ${ }^{14}$.

Para além dos fatores epidemiológicos "puros", o comportamento humano é fundamental para a disseminação do SARS-CoV-2, bem como para a sua redução ${ }^{15}$. Assim, objetivamos a produção de uma linguagem efetiva e simples para os protocolos. Essa escolha linguística busca sobretudo facilitar a aplicação dos protocolos ao mesmo tempo em que visa contribuir para uma possível mudança de comportamento, no que se refere a cuidados no momento da aquisição de gêneros alimentícios.

Posteriormente à verificação da estrutura científica que embasou a construção da estratégia protocolar, as informações foram dispostas em uma lógica que trata os envolvidos e os produtos como potencialmente contaminados e contaminadores, visando diminuir a possibilidade de contágio e contaminação no processo. Após a determinação dos possíveis vetores de contaminação, as informações e orientações de prevenção de contágios foram condensadas em três cenários de compras e entregas de mercadorias para supermercados e "mercadinhos". Em seguida, esses cenários descritos nos protocolos orientaram a construção de folhetos, os quais tiveram, com apoio de artes gráficas, o objetivo de permitir uma maior compreensão para diversos públicos. Elaboramos um folheto para cada um dos três cenários. Cada folheto, por sua vez, foi dividido em quatro partes: A, B, C e D.

Parte A: "Informações gerais", composta por orientações iniciais diversas sobre higiene e aplicação do protocolo.

Parte B: "Pedindo as compras", uma seção mais curta constante em todos os protocolos, introduzindo orientações sobre a higienização dos produtos e a identificação do processo de entrega.

Parte C: "Informações sobre higienização e entrega dos produtos", que figura em todos os protocolos e sugere atitudes em relação à higienização adequada, ao tipo de recipiente utilizado na entrega e à composição utilizada na higienização.

Parte D: "Entregando/Recebendo as compras" contém informações mais detalhadas sobre os procedimentos de higiene pessoal e dos produtos durante e após a entrega.

\section{RESULTADOS E DISCUSSÃO}

Para evitar repetições desnecessárias e consideradas as limitações deste gênero textual, expomos aqui apenas o protocolo 1 , que trata de compras realizadas por meio da modalidade delivery com pagamento efetuado por meio de cartão de crédito/ débito, com as devidas referências, seguido do seu respectivo folheto, resultado final do trabalho ilustrativo.

\section{PROTOCOLO DE COMPRA POR DELIVERY EM SUPERMERCADOS E MERCADINHOS}

\section{CENÁRIO 1 - Pagamento por cartão de crédito/débito}

\section{INFORMAÇÕES GERAIS}

1. No momento da entrega, cliente e entregador devem usar máscaras (preferencialmente reutilizáveis) ${ }^{4}$.

2. O uso de luvas descartáveis pelo entregador e cliente garante maior segurança.

3. Cliente e entregador não devem tocar os próprios olhos, boca e nariz até o fim de toda operação de entrega ${ }^{14}$.

4. Nessa modalidade de compra, deve-se disponibilizar mesa(s) ou cadeira(s) na entrada de casa para colocar as mercadorias e a maquineta do cartão.

5. Se possível, deve-se disponibilizar balde(s) ou mangueira(s), borrifador(s) e produtos de limpeza (sabão, álcool, água sanitária e detergentes) para efetuar a higienização dos produtos na entrada da casa.

6. Ao retornar ao local de trabalho, a maquineta deve ser higienizada com produtos próprios para essa atividade e quem o fizer deve higienizar as mãos ao final. A maquineta protegida com capa ou envolta em papel filme facilita sua higienização e dificulta danos ao aparelho.

7. Morando em condomínio, deve-se informar na guarita ou ao porteiro sobre a vinda das compras, bem como a existência deste protocolo.

8. Havendo normas do condomínio para entregas, o estabelecimento comercial deve ser informado.

9. Ao entregar as compras em caixas de papelão, o entregador só retira os produtos da caixa a pedido do cliente, caso este necessite de ajuda.

\section{PEDINDO AS COMPRAS}

1. Verifique o encarte de preços do supermercado/mercadinho antes de efetuar os pedidos.

2. Faça a lista de pedidos detalhando quantidades, volumes $(\mathrm{g} / \mathrm{ml})$ e marcas de produtos.

3. Entre em contato com o local das compras e repasse a lista dos pedidos (WhatsApp facilita a comunicação porque é mais acessível).

4. Após organizadas as compras, o estabelecimento deve entrar em contato com o cliente avisando o valor e repassando o cupom fiscal para que o cliente confira. 


\section{INFORMAÇÕES SOBRE HIGIENIZAÇÃO E ENTREGA DOS PRODUTOS}

1. Higienização dos produtos: feita através de mistura de água e sabão ou água e água sanitária $25 \mathrm{ml}$ (aproximadamente 2 colheres de sopa de água sanitária para cada litro d'água) ${ }^{16}$, lavando as embalagens que puderem ser lavadas ou, ainda, usando álcool etílico (líquido ou em gel sempre na concentração mínima de $70 \%$ ), para limpeza com auxílio de papel toalha ou um pano limpo, nas embalagens e nos produtos que não puderem ser lavados.

2. Entrega com caixa de papelão: ao serem usadas caixas de papelão nas entregas, elas devem ser desocupadas (retirar as compras), totalmente higienizadas (molhadas com água e sabão) e, logo em seguida, descartadas (se possível cortadas, amassadas e colocadas em sacos plásticos). Não sendo possível o descarte imediato, guardá-las em local que dificulte um contato acidental.

3. Entrega com caixas plásticas: usando caixas plásticas nas entregas, elas devem ser desocupadas pelo entregador (retirar as compras), que deve colocar as mercadorias nos locais vagos da(s) mesa(s) e cadeira(s). Essas caixas devem ser higienizadas ao retornarem ao estabelecimento comercial para que uma nova entrega seja realizada com segurança.

4. Dinheiro: após toda manipulação com dinheiro, deve-se higienizar mãos, pois cédulas e moedas têm elevada chance de produzir contaminação.

\section{ENTREGANDO/RECEBENDO AS COMPRAS}

1. Os dois envolvidos devem manter sempre a distância mínima de 2 metros um do outro ${ }^{14}$.

2. O estabelecimento deve enviar o cupom fiscal das compras ao cliente, também via redes sociais, avisando ainda o horário da saída e o nome do entregador.

3. Chegando à residência do cliente, o entregador deve avisar sua chegada por campainha, telefone, porteiro ou com a própria voz, identificando-se pelo nome do estabelecimento.

4. O entregador, após ser ouvido, afasta-se da porta de entrada para manter a distância mínima de 2 metros quando o cliente for abri-la.

5. Ao abrir a porta, o cliente também deve se afastar para manter a distância mínima de 2 metros para permitir a entrada do entregador, caso sua entrada seja necessária.

6. Atenção: não sendo possível efetivar a colocação das compras na(s) mesa(s) e cadeira(s) da porta/portaria, o entregador deve adentrar o mínimo possível na residência, fazendo-o em linha reta e voltando pelo mesmo espaço pelo qual entrou.

7. O cliente deve colocar um pano molhado com a mistura de água com água sanitária na entrada da casa, para o entregador limpar o solado do calçado, caso precise adentrar na casa.

8. O entregador deve colocar a(s) caixa(s) com as compras na(s) mesa(s) ou cadeira(s), retirar as compras da(s) caixa(s), (caso o cliente peça ou necessite de ajuda), colocando-as nos espaços vazios da(s) cadeira(s) ou mesa(s) e a maquineta já pronta para o uso. Posteriormente, o entregador deve afastar-se no mínimo 2 metros e pedir ao cliente que efetue o pagamento.

9. O cliente deve efetuar o pagamento antes de manipular as compras, pois, ao fazer a higienização das compras com a presença da maquineta, corre o risco de molhá-la.

10. Feito o pagamento, o cliente coloca o comprovante para a loja embaixo da maquineta, afasta-se e pede ao entregador que a recolha. É importante que o comprovante do cliente seja colocado em uma sacola plástica higienizada. 0 cartão de crédito deve ser colocado próximo às compras para também ser higienizado.

11. Após a manipulação da maquineta, o entregador deve guardá-la e os dois envolvidos devem higienizar as mãos, lembrando sempre de manter a distância mínima de 2 metros um do outro.

12. Depois de guardar a maquineta, o entregador deve recolher o comprovante de pagamento da loja e a caixa plástica em que levou as compras (caso a entrega tenha sido feita numa), agradecer ao cliente e sair da residência para retornar ao local de trabalho.

13. Após a saída do entregador, o proprietário deve lavar os locais percorridos pelo entregador dentro da residência (caso essa movimentação tenha ocorrido), lembrando de lavar também os próprios pés, pernas e mãos enquanto realiza essa limpeza.

14. Antes de higienizar as compras, o cliente deve higienizar uma superfície vaga na(s) mesa(s) ou cadeira(s) para colocar as compras após serem limpas.

15. Posteriormente, passa a higienizar as compras, limpando todos os produtos que possam ser higienizados diretamente (os que não podem devem ter suas embalagens higienizadas), sempre colocando os produtos já higienizados na superfície limpa.

16. A seguir, deve-se higienizar a superfície onde eles foram colocados pelo entregador ao retirá-los da caixa, limpando também cerca de 2 metros ao redor dessa superfície.

17. O cliente deve esperar os produtos secarem antes de transportá-los para dentro de casa.

18. Frutas, verduras e ovos, após terem suas embalagens higienizadas, devem ser transportadas para uma pia e lavadas antes de serem guardadas.

19. Ao final de todas as atividades, deve-se tomar um banho. 
Após a elaboração criteriosa dos protocolos considerando-se as diversas recomendações de especialistas, seguiu-se a segunda etapa: a confecção de folhetos ilustrados (Figuras 1, 2 e 3). 0 objetivo principal desses folhetos é funcionar como amplificadores de possibilidades de divulgação, utilizando as redes sociais, por exemplo, e simplificadores da linguagem contida na parte escrita dos três cenários construídos.

A produção dos protocolos e dos folhetos seguiu duas etapas: a primeira referente à reunião de todas as informações especializadas sobre as formas de contaminação para proceder à elaboração do texto de modo que sua leitura se desse de forma inteligível e prática e a segunda etapa, à transformação do texto dos protocolos em uma apresentação mais visualmente agradável, ilustrada e colorida. Por essa razão, apresentamos acima a primeira versão do texto, com referências às informações coletadas que o embasaram e a segunda versão, já ilustrada. Os outros cenários ( 2 e 3): pagamento com dinheiro e pagamento por
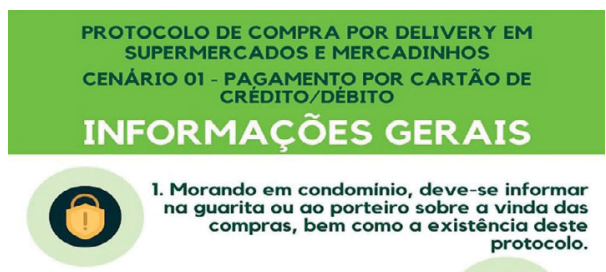

1. Morando em condominio, deve-se informar na guarita ou ao porteiro sobre a vinda das
compras, bem como a existência deste 2. Havendo normas do condominio para entregas, o estabel
deve ser informado.

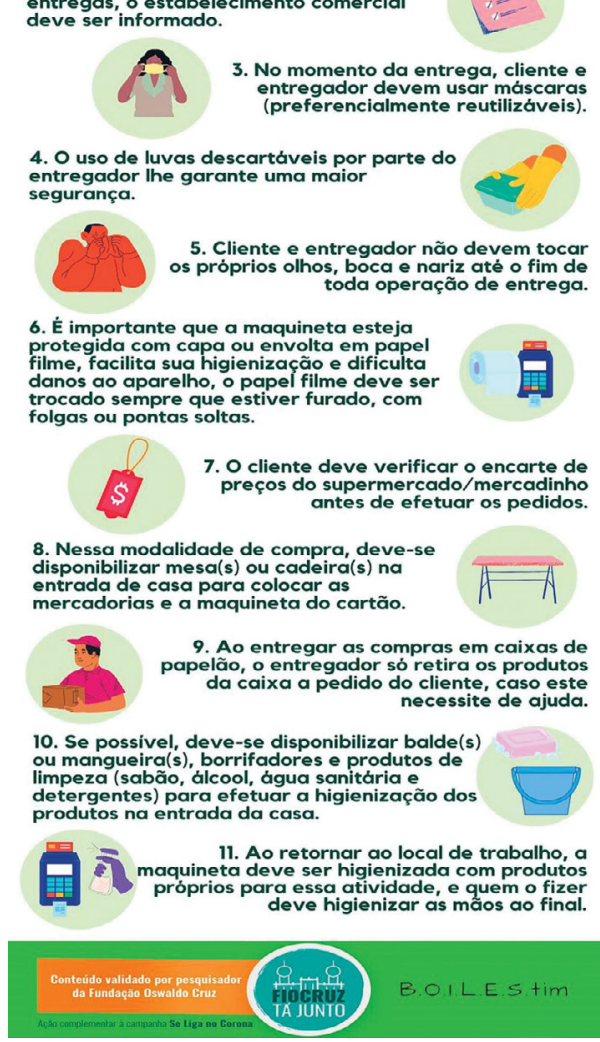

Fonte: Elaborada pelos autores, 2020.

Figura 1. Folheto do cenário 1 - Pagamento por cartão de crédito/ débito: informações gerais. transferência bancária podem ser encontrados em https://sites. google.com/ifpi.edu.br/boiles/covid19/protocolos?authuser=0.

Para o processo de produção desses materiais foi necessário realizar um grande apanhado de informações sobre as práticas atuais de compras, sobre o funcionamento de compras em formato delivery e sobre práticas recomendadas pelos pesquisadores, sobretudo da saúde e áreas afins, acerca da devida higienização durante e após as compras. Na busca por validação de pesquisadores especialistas, conseguiu-se selo de validação junto à renomada Fundação Oswaldo Cruz, por meio de ação complementar à campanha "Se Liga no Corona" 17 .

É interessante relembrar, como já ressaltado na introdução, a importância desse trabalho de conscientização na medida em
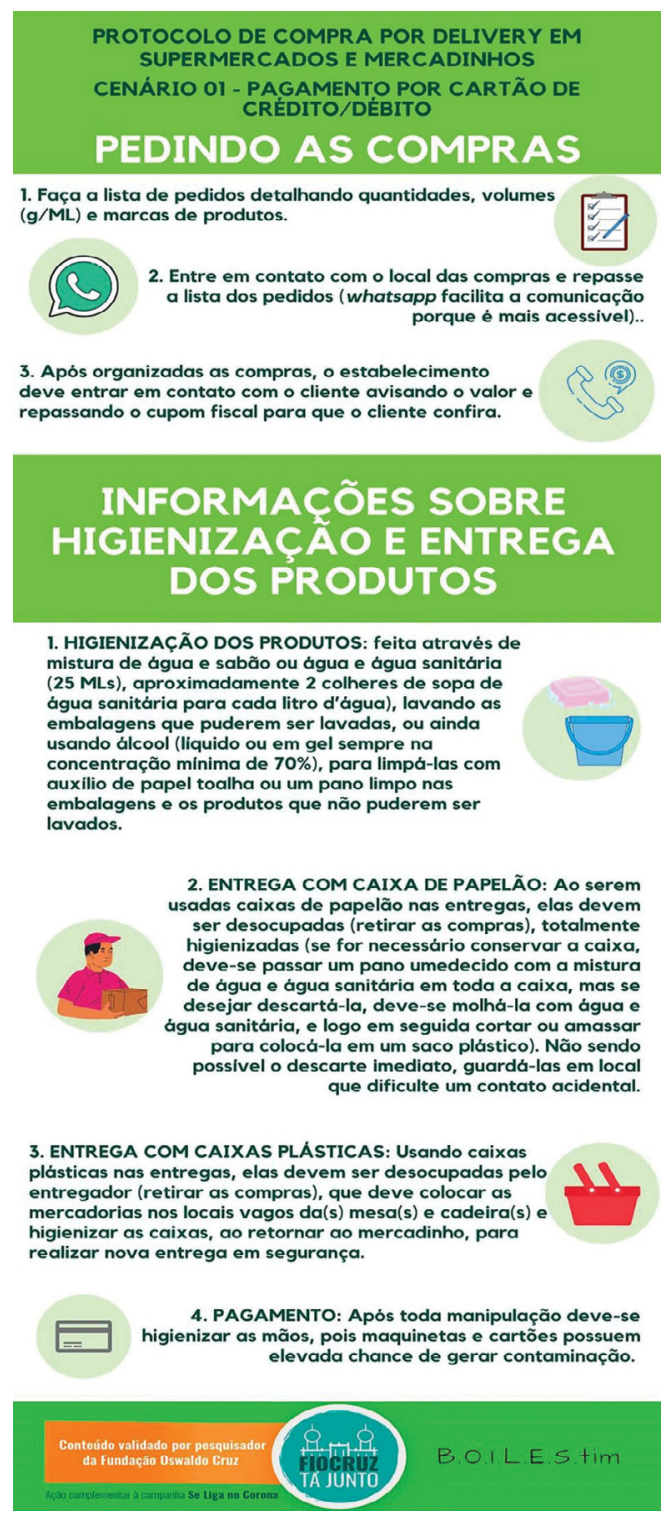

Fonte: Elaborada pelos autores, 2020.

Figura 2. Folheto do cenário 1 - Pagamento por cartão de crédito/ débito: pedindo as compras e Informações sobre higienização e entrega dos produtos. 


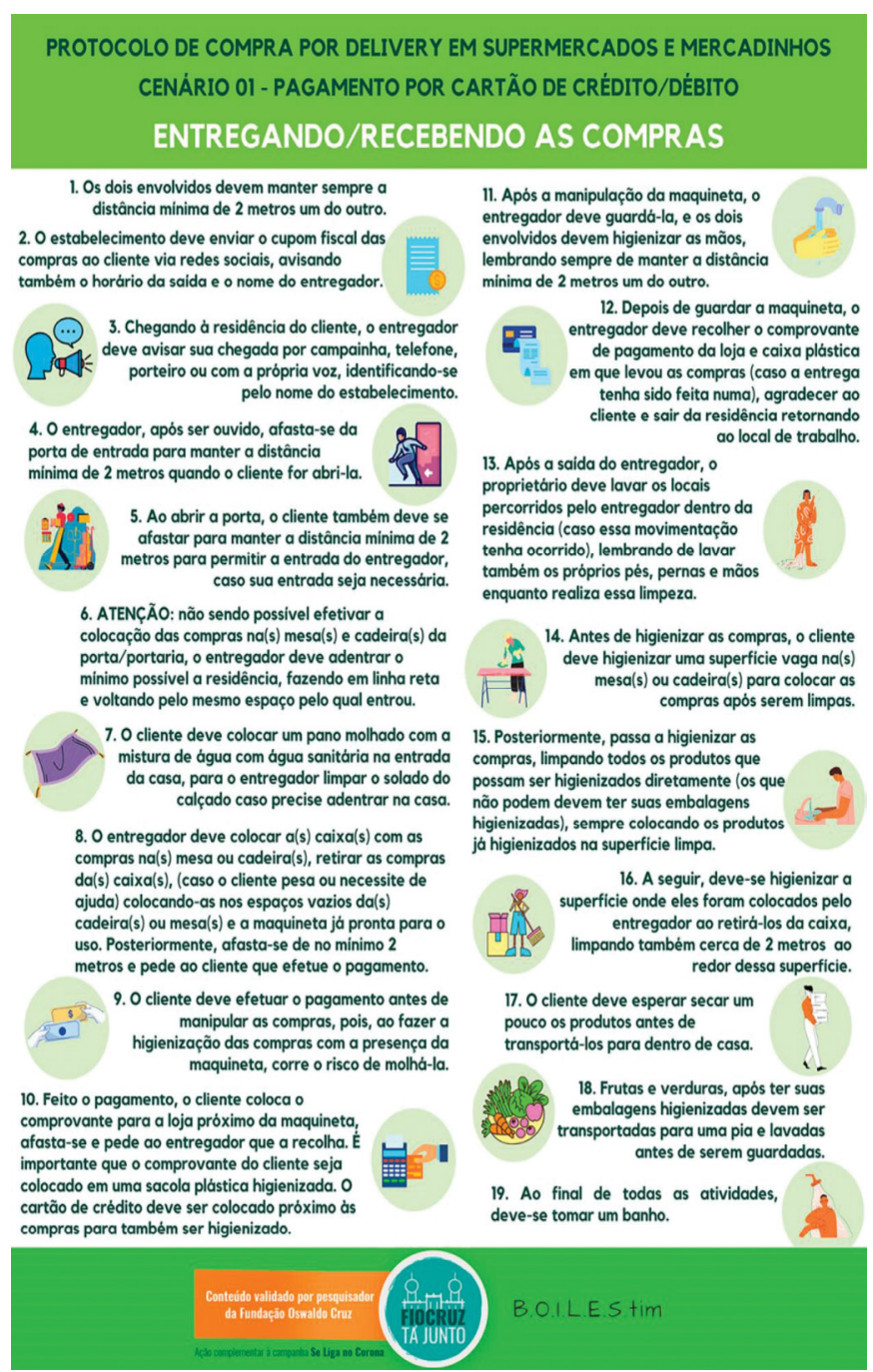

Fonte: Elaborada pelos autores, 2020.

Figura 3. Folheto do cenário 1 - Pagamento por cartão de crédito/débito: entregando/recebendo as compras.

que os números de pesquisas apontam para uma explosão de entregas em formato delivery, já em aumento significativo com a popularização da internet, no contexto de pandemia, em que a ação pública de combate mais recomendada mundialmente é o distanciamento social.

\section{CONCLUSÕES}

Nesse momento da crise no país, quando os números de contaminados e mortos avançam assustadoramente, é preciso fomentar o máximo possível a ciência e sua colaboração contra a COVID-19 e auxiliar na produção de melhores condições de trabalho para os profissionais de serviços essenciais e pesquisadores envolvidos no controle da pandemia.

Além disso, deve-se trabalhar no sentido de produzir orientações qualificadas e informações confiáveis para a população em geral, popularizar essas informações, simplificar sua linguagem e divulgá-las em vários formatos e mídias, buscando uma diminuição significativa da possibilidade de contágio viral individual e coletivo.

Após uma rápida análise de conjuntura, apresentou-se os protocolos que vislumbram, como resultado prático, a construção de passos lógicos e de fácil entendimento que possam ser replicados por diversos tipos de pessoas em suas heterogeneidades econômicas, educacionais e habitacionais. Portanto, identifica-se a estrutura produzida como um base de orientação, não sendo de forma alguma uma estrutura rígida que não possa ser adaptada. Como exemplo podemos destacar que as diferentes formas de moradas (casa, condomínios, prédios, chácaras etc.) e as peculiaridades de cada morador (como o fato de apresentar ou não limitações de locomoção) interferem na forma de utilização do protocolo.

Esse trabalho faz parte de um projeto maior, do qual os próximos passos são: elaborar material animado a partir dessa mesma base protocolar, avaliar a aplicabilidade dos folhetos, acompanhar sua eficácia e possíveis necessidades de reformulação. 


\section{REFERÊNCIAS}

1. Callaway E. Coronavirus vaccine trials have delivered their first results: but their promise is still nuclear. Nature Magazine. 21 maio 2020.

2. World Health Organization - WHO. Coronavirus disease (COVID-19) advice for the public. Geneva: World Health Organization; 2020[acesso 11 jun 2020]. Disponível em: https://www.who.int/emergencies/diseases/ novel-coronavirus-2019/advice-for-public

3. Unidade de Gestão Estratégica - UGE. O impacto da pandemia de coronavírus nos pequenos negócios. Brasília: Serviço Brasileiro de Apoio às Micro e Pequenas Empresas; 2020[acesso 11 jun 2020]. Disponível em: https://datasebrae.com.br/wp-content/ uploads/2020/04/Impacto-do-coronav\%C3\%ADrus-nas-MPE2\%C2\%AAedicao_geral-v4-1.pdf

4. World Health Organization - WHO. Coronavirus disease (COVID-19) advice for the public: when and how to use masks. Geneva: World Health Organization; 2020[acesso 29 jun 2020]. Disponível em: https: / /www. who.int/emergencies/diseases/novel-coronavirus-2019/ advice-for-public/when-and-how-to-use-masks

5. Garcia LP. Uso de máscara facial para limitar a transmissão da COVID-19. Epidemiol Serv Saude. 2020;29(2):1-4. https://doi.org/10.5123/S1679-49742020000200021

6. He X, Lau EHY, Wu P, Deng X, Wang J, Hao

$X$ et al. Temporal dynamics in viral shedding and transmissibility of COVID-19. Nat Med. 2020;26(5):672-5. https: / / doi.org/10.1038/s41591-020-0869-5

7. Silva AAM. Sobre a possibilidade de interrupção da epidemia pelo coronavírus (COVID-19) com base nas melhores evidências científicas disponíveis. Rev Bras Epidemiol. 2020;23:1-3. https://doi.org/10.1590/1980-549720200021

8. Xu R, Cui B, Duan X, Zhang P, Zhou X, Yuan Q. Saliva: potential diagnostic value and transmission of 2019-nCoV. Int J Oral Sci. 2020;12(1):1-6. https://doi.org/10.1038/s41368-020-0080-z

9. Doremalen N, Morris DH, Holbrook MG, Gamble A, Williamson BN, Tamim A et al. Aerosol and surface stability of SARS-CoV-2 as compared with SARS-CoV-1. N Engl J Med. 2020;382:1564-7. https://doi.org/10.1056/NEJMc2004973

10. Chin AWH, Chu JTS, Perera MRA, Hui KPY, Yen HL, Chan MCW et al. Stability of SARS-CoV-2 in different environmental conditions. Lancet Microb. 2020;1:10. https://doi.org/10.1016/S2666-5247(20)30003-3

11. Agência Nacional de Vigilância Sanitária - Anvisa. Orientações gerais para higiene das mãos em serviços de saúde. Brasília: Agência Nacional de Vigilância Sanitária; 2018[acesso 11 jun 2020]. Disponível em: https://www20.anvisa.gov.br/ segurancadopaciente/index.php/publicacoes/item/notatecnica-n-01-2018-gvims-ggtes-anvisa-orientacoes-geraispara-higiene-das-maos-em-servicos-de-saude-2

12. Oliveira WK, Duarte E, França GVA, Garcia LP. Como o Brasil pode deter a COVID-19. Epidemiol Serv Saude. 2020;29(2):1-8. https://doi.org/10.5123/S1679-49742020000200023

13. Oliveira $A C$, Lucas TC, Iquiapaza RA. O que a pandemia da COVID-19 tem nos ensinado sobre adoção de medidas de precaução? Texto Contexto Enferm. 2020;29:1-15. https://doi.org/10.1590/1980-265X-TCE-2020-0106

14. Ministério da Saúde (BR). Coronavírus: o que você precisa saber. Brasília: Ministério da Saúde; 2020[acesso 29 jun 2020]. Disponível em: https://coronavirus.saude.gov.br/ sobre-a-doenca\#como-se-proteger

15. West R, Michie S, Rubin GJ, Amlot R. Applying principles of behaviour change to reduce SARS-CoV-2 transmission. Nat Hum Behav. 2020;4(5):451-9. https://doi.org/10.1038/s41562-020-0887-9.

16. Macedo JAB. Solução caseira para eliminar o coronavírus da sua casa. Brasília: Conselho Federal de Química; 2020[acesso 11 jun 2020]. Disponível em: http://cfq.org.br/noticia/ solucao-caseira-para-eliminar-o-coronavirus-da-sua-casa/

17. Fundação Oswaldo Cruz - Fiocruz. Campanha se liga no corona. Rio de Janeiro: Fundação Oswaldo Cruz; 2020[acesso 11 jun 2020]. Disponível em: https://portal.fiocruz.br/se-liga-no-corona

Contribuição dos Autores:

Melo HD - Concepção, planejamento (desenho do estudo), análise e interpretação dos dados e redação do trabalho. Lopes SLC, Rodrigues MEM - Análise, interpretação dos dados e redação do trabalho. Alves WA - Construção gráfica dos encartes e do site onde estão hospedados os protocolos. Almondes RC - Construção gráfica dos encartes dos protocolos. Carvalho VM - Construção e manutenção do site onde estão hospedados os protocolos. Araujo DAST, Carvalho RM - Estruturação dos dados econômicos do trabalho. Todos os autores aprovaram a versão final do trabalho.

Conflito de Interesse

Os autores informam não haver qualquer potencial conflito de interesse com pares e instituições, políticos ou financeiros deste estudo. 